\title{
Design And Performance Analysis of Rectangular Microstrip Patch Antenna With Half-Hexagonal Fractal Techniques
}

\author{
${ }^{*}$ Lovepreet Singh ${ }^{1}$, Mandeep Singh ${ }^{2}$, Mandeep Kaur ${ }^{3}$ \\ ${ }^{1}$ (M.Tech Student, Department of Electronics and Communication Engineering, Punjabi University Patiala, India, \\ ${ }_{2}^{2}$ (Phd Student, Department of Electronics and Communication Engineering, Punjabi University Patiala, India, \\ ${ }^{3}$ (Assistant Professor,Department of Electronics and Communication Engineering, Punjabi University Patiala, India \\ Corresponding author: $*$ Lovepreet Singh
}

\begin{abstract}
The compact size of antenna is becoming necessity for advancement in modern technology. In this paper, the design and analysis of rectangular Microstrip patch antenna with half hexagonal fractal geometry has been proposed. The proposed antenna operates at multi-resonant frequencies. The dielectric material Roger RT duroid/5880 has been employed as a substrate material for designing the proposed antenna having thickness $2 \mathrm{~mm}$ with relative permittivity $\left(\varepsilon_{\mathrm{r}}\right)$ of 2.2 with loss tangent $(\delta) 0.0009$. The Co-axial feed line has been used to fed the power to the antenna with proper impedance matching of $50 \Omega$ so maximum power can transfer. The performance of proposed antenna has been analyzed in terms of return loss $(\mathrm{dB})$, gain $(\mathrm{dB})$, directivity $(\mathrm{dBi})$ and VSWR. The proposed antenna design can be used for $\mathrm{S}$ band, $\mathrm{C}$ band and $\mathrm{X}$ band applications such as weather forecasting, military, satellite communication, wireless communication and radar. The High Frequency Structure Simulator (HFSS) v.13.0 has been used for the analysis and simulation of proposed antenna.

Keywords:-Co-axial feed; Gain; Hexagonal fractal geometry; Microstrip Antenna; Multi-resonant; High Frequency Structure Simulator (HFSS); Roger RT duroid/5880;
\end{abstract}

\section{INTRODUCTION}

Modern radar and wireless communication systems demand antenna that are light in weight, easy to excite, fabricate and operate over the wide range of frequency should be adaptable with changing system. In order to fulfill the requirements of low profile, low cost, small size, ease of fabrication and multiband characteristics, mostly microstrip patch antennas are employed with optimal design [1].

The fractal geometries have been used to fabricate multi-band and broad-band antennas. The definition of fractal geometry is given by B.Mandelbort in 1975 and its meaning is irregular [2].Each fractal is self-assured of multiple iteration of a single elemental shape. Fractal geometry has self-similar and space filling property [3]. These pattern no doubt looks complex but because of their self-similarity are very simple geometry. Fractal geometry helps to increase the effective length of antenna by keeping the total area same. The operation of fractal geometry is quite genuine. The starting known as Initiator is an origin, which is partition into equivalent parts [4]. This is the first iterated version of the geometry and called first iteration. For generation of higher iterations, the process of fractal geometry has been reused again and again. There are a number of available shapes for fractal antenna such as Sierpinski carpet, Sierpinski gasket, Koch, Hilbert curves, rectangular, triangular, half hexagonal, circular etcetera that are employed for the designing of antennas. Their main purpose of using fractal geometry is to increase the electrical length of antenna without affecting the radiation characteristics of the conventional antenna. The space-filling properties of some fractal shapes the fractal dimension might allow fractal shaped small antennas better to take advantage of the small surrounding space [5].

There are different types of techniques has been employed in order to feed the antenna such as microstrip line [6], coaxial probe [7], coplanar waveguide [8] etc. Each feeding technique is used for different application

purpose. In this paper, co-axial probe has been used for feeding purpose. In co-axial probe feed, inner conductor has been connected to the radiation patch while the outer conductor has been connected to the ground plane. The prime advantage of co-axial probe 
feed because it has low spurious losses. Coaxial probe is also helpful for impedance matching with antenna

\section{ANTENNA DESIGN}

Fractal configuration exists in different forms such as rectangular, triangular, half hexagonal, circular etc.This paper presented the half hexagonal shape fractal made cut along the sides of the rectangular patch. There are three important parameters resonant frequency $\left(f_{r}\right)$, dielectric material of the substrate $\left(\varepsilon_{r}\right)$ and height of substrate (h) are mainly used for designing of patch antennas. The Roger RT duroid/5880 is the dielectric material employed for antenna substrate having dielectric constant 2.2 with thickness of $2 \mathrm{~mm}$ and loss tangent 0.0009 .

Patch width of antenna is calculated by using transmission line model equations as given in [9-11].

$w=\frac{1}{2 f_{r} \sqrt{\mu_{o} \varepsilon_{o}}} \sqrt{\frac{2}{\varepsilon_{r}+1}}=\frac{v_{o}}{2 f_{r}} \sqrt{\frac{2}{\varepsilon_{r}+1}}(1)$

Where, $\varepsilon_{r}=$ Dielectric permittivity

$f_{r}=$ Resonant frequency

$v_{o}=$ velocity of light

The effective dielectric constant can be obtained by [10-11]

$\varepsilon_{r e f f}=\frac{\epsilon_{r}+1}{2}+\frac{\varepsilon_{r}-1}{2}\left[1+12 \frac{h}{W}\right]^{-\frac{1}{2}}$

Where, $\mathrm{h}=$ thickness of the substrate

$\varepsilon_{r}=$ Dielectric permittivity

$\mathrm{w}=$ width of the antenna

The dimensions of the patch along its length is extended on each end by a distance of $\Delta \mathrm{L}$ due to fringing effect, which is given by

$\Delta L$

$=h \frac{\left(\varepsilon_{\text {reff }}+0.3\right)\left(\frac{W}{h}+0.264\right)}{\left(\varepsilon_{\text {reff }}-0.258\right)\left(\frac{W}{h}+0.8\right)}$

The actual length $\mathrm{L}$ of the antenna is given by [9-11]

$L=\frac{1}{2 f_{r} \sqrt{\varepsilon_{r e f f}} \sqrt{\mu_{o} \varepsilon_{o}}}-2 \Delta L(4)$

The top and bottom views of the proposed antenna design have been shown in the fig. 1 and fig. 2 , respectively. The ground plane has been employed at the bottom of the substrate having dimensions $40 * 46$ $\mathrm{mm}^{2}$. The radiating patch of the proposed antenna design has been placed just above the substrate. The dimensions of rectangular patch of the proposed design are calculated by Eq. (1) and Eq. (2) and found to be $30.55 * 37.05 \mathrm{~mm}^{2}$. The design of the proposed antenna illustrates in fig. 1 and fig. 2 with top view and bottom view. The power is fed to the proposed antenna through the Co-axial feed line having impedance $50 \Omega$ with proper impedance matching to SMA connector to transfer maximum power from source to load. The proper impedance matching results good return loss and to avoid spurious losses, in the proposed antenna design, the coaxial feed line point along the diagonal shape with diameter of $2 \mathrm{~mm}$ has been contacted between the patch and ground plane.

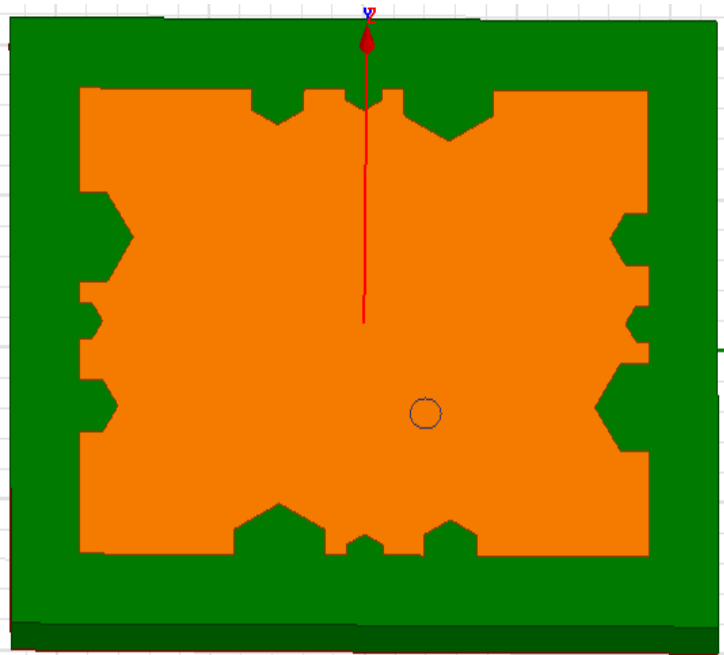

Fig.1The top view of the proposed antenna design

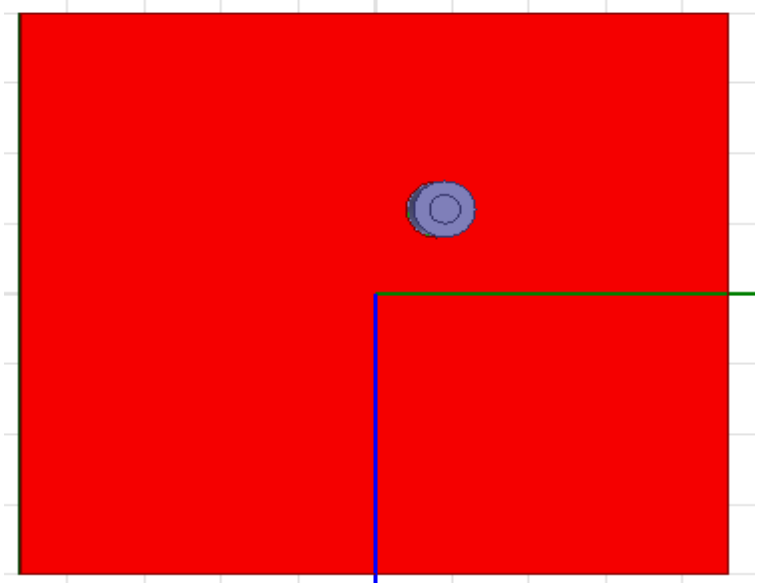

Fig.2 The bottom view of the proposed antenna design 


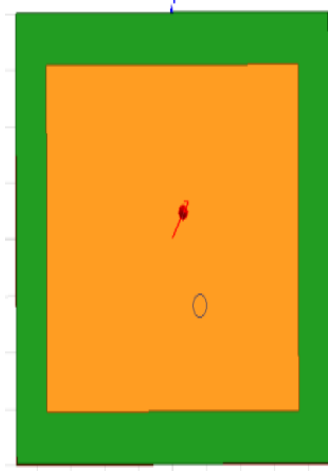

Initiator

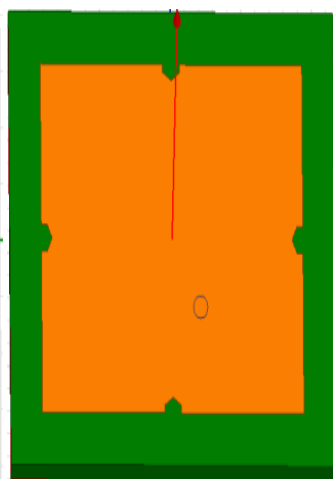

Stage-1
Fig. 3 Initiator and iteration process at stage- 1 for the proposed antenna design

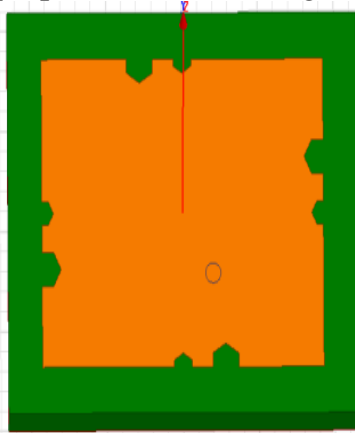

Stage-2

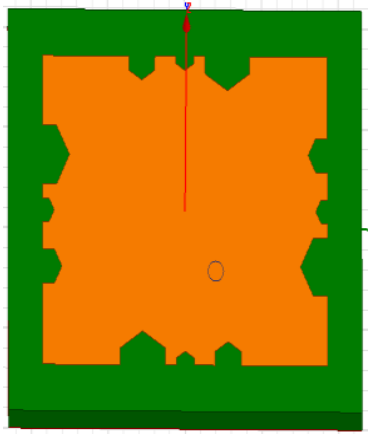

Stage-3
Fig.4 Iteration process at stage- 2 and stage- 3 for the proposed antenna design

Fig. 3and fig. 4 shows the iteration process of proposed antenna design. The design process has been started with rectangular geometry that is also known as initiator as shown in fig. 3, the dimensions for the rectangular geometry has been calculated by using equation 1to equation 4. To perform the fractal geometry, a half hexagonal with dimension $1.5 \mathrm{~mm}$ is cut from the middle of four sides of the rectangular geometry and these half hexagonal are of same dimensions that have been shown in fig. 3 iteration process at stage 1 of the designing antenna. In stage2, another half hexagonal with dimension $2.48 \mathrm{~mm}$ is deployed on each side of the patch and the sizes of these half hexagonal are larger than size of half hexagonal that are used in stage1. In the stage-3, half hexagonal with dimension $3.5 \mathrm{~mm}$ has been subtracted from four sides of rectangular patch that have larger size of half hexagonal other than two half hexagonal shapes that have been deployed in stage1 and stage2, shown in fig. 4.

\section{SIMULATION RESULT}

The proposed antenna having a gain of $8.23 \mathrm{~dB}, 6.93 \mathrm{~dB}$ and $6.11 \mathrm{~dB}$ and directivity of $6.58 \mathrm{dBi}$, $4.93 \mathrm{dBi}$ and $1.19 \mathrm{dBi}$ at resonant frequency of 9.47
$\mathrm{GHz}, 7.95 \mathrm{GHz}$ and $5.97 \mathrm{GHz}$ with return loss of $43.02 \mathrm{~dB},-12.41 \mathrm{~dB}$ and $-20.27 \mathrm{~dB}$ respectively.

The presented antenna has been analyzed in terms of return loss $(\mathrm{dB})$, gain $(\mathrm{dB})$, directivity $(\mathrm{dBi})$ and VSWR using High Frequency Structure Simulator (HFSS) v.13.0. The Simulation result for three iterations of proposed antenna has been shown in below figures. The proposed antenna has been designed to resonant at different multi-resonant frequencies like as $2.99 \mathrm{GHz}, 5.21 \mathrm{GHz}, 5.97 \mathrm{GHz}, 7.95 \mathrm{GHz}, 8.76 \mathrm{GHz}$ and $9.47 \mathrm{GHz}$ with return loss of $-16.98 \mathrm{~dB},-17.32 \mathrm{~dB}$, $-20.28 \mathrm{~dB},-12.41 \mathrm{~dB},-13.91 \mathrm{~dB}$ and $-43.02 \mathrm{~dB}$ respectively. Fig. 5 illustrates the return loss plot of three stages for the proposed antenna, red curve represents first stage of iteration, purple curve indicates second stage iteration and green curve represents third stage of iteration for the fractal geometry. The improvements in the results have been found in successive iteration stage, when the fractal technique has been applied on the rectangular patch. The fig. 6 represents the return loss plot for the proposed antenna with stage-3 of iteration for fractal geometry.fig.7, 8 and 9 shows VSWR, overall Gain and overall Directivity of proposed antenna respectively.

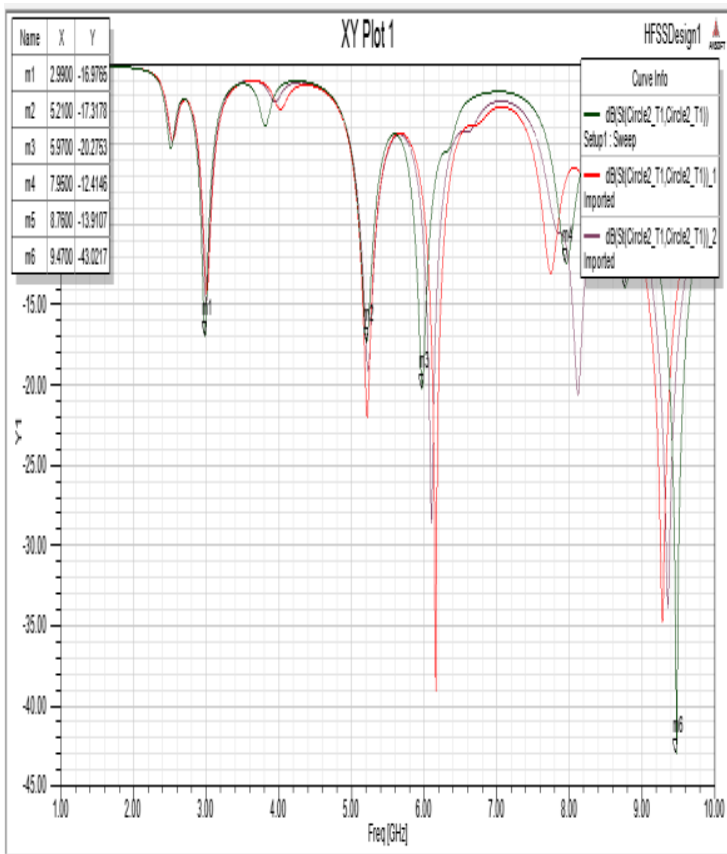

Figure.5 Return loss of different stage of proposed antenna 


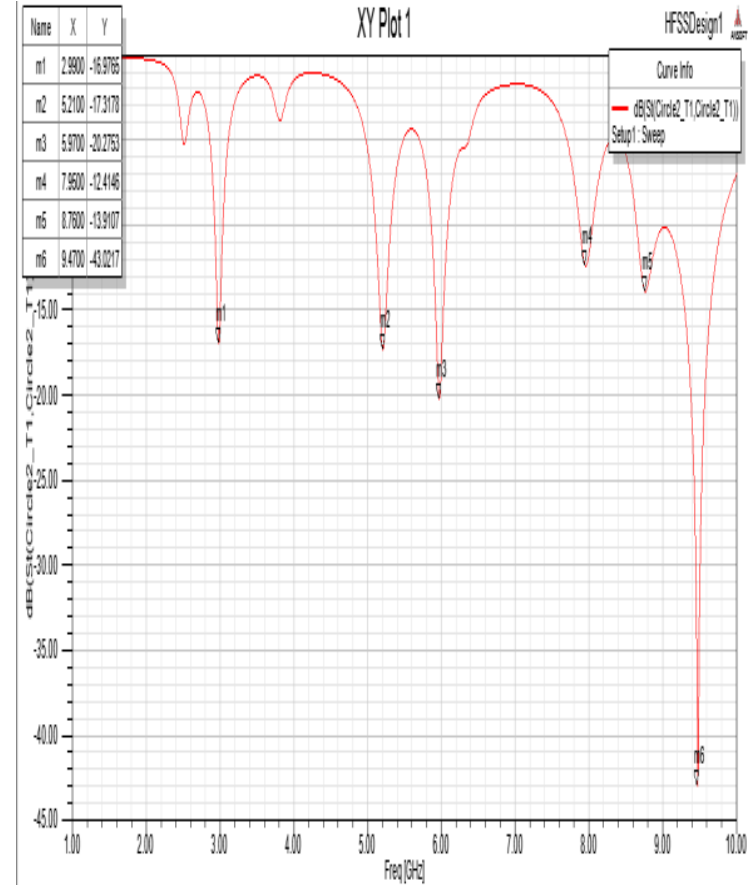

Figure.6 Return loss of proposed antenna design

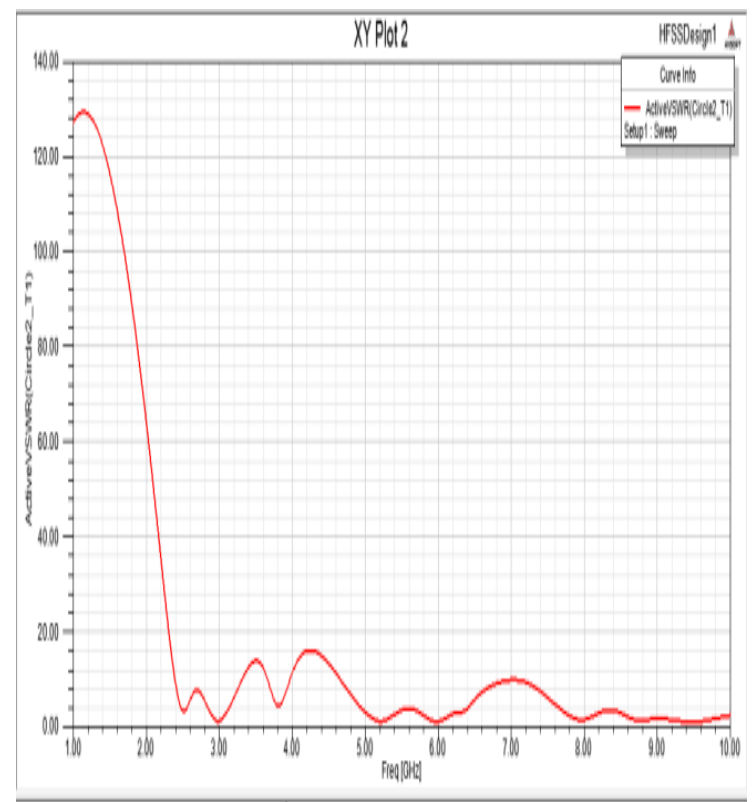

Figure.7 VSWR of proposed antenna design

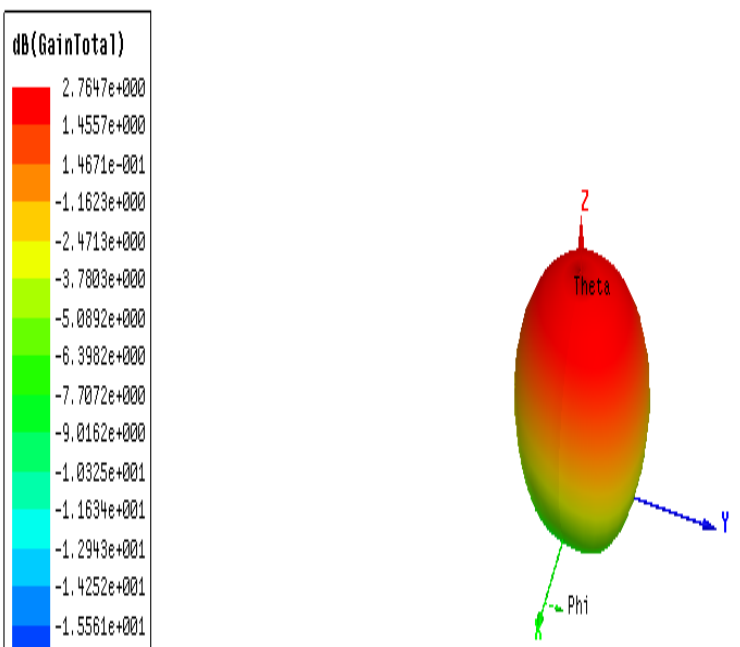

$-1,68706+601$

$-1,8179 e+601$

Figure.8 overall Gain of proposed design

\begin{tabular}{|c|c|c|c|c|}
\hline $\begin{array}{c}\text { FREQUENCY } \\
(\mathrm{GHz})\end{array}$ & $\begin{array}{c}\text { RETURN } \\
\text { LOSS } \\
(\mathrm{dB})\end{array}$ & VSIRR & $\begin{array}{c}\text { GAN } \\
(\mathrm{dB})\end{array}$ & $\begin{array}{c}\text { DIRETIVITY } \\
(\mathrm{dB})\end{array}$ \\
\hline 2.99 & -16.98 & 1.38 & 3.18 & 1.82 \\
\hline 5.21 & -17.32 & 1.32 & 3.67 & 2.39 \\
\hline 5.97 & -20.28 & 1.43 & 6.11 & 1.19 \\
\hline 7.95 & -12.41 & 1.91 & 6.94 & 4.93 \\
\hline 8.76 & -13.91 & 1.90 & 4.71 & 2.85 \\
\hline 9.47 & -43.02 & 1.29 & 8.23 & 6.58 \\
\hline
\end{tabular}

\section{I . Table}

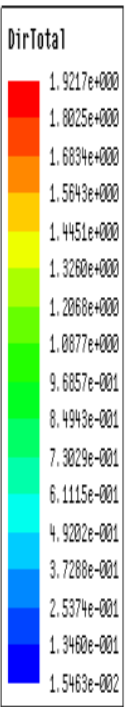

Figure.9 overall Directivity of proposed design 
Performance Parameters For Third Iteration The performance parameters for the proposed antenna such as Return loss, Gain, Directivity and VSWR for 3rd iteration has been calculated and their numerical values are shown in Table-1.

\section{CONCLUSION}

This paper presents the design of microstrip patch antenna with half hexagonal. It can be concluded from the above discussion that performance parameters of antenna have been improved by using half hexagonal

\section{REFERANCES}

[1]. Fnjimoto K, Henderson A, Hirasawa K and James J R,’Small Antennas," New York, John Wiley \& Sons, Research Studies Press, 1987.

[2]. Cohen,N., "Fractal antenna applications in wireless telecommunications, "IEEE Electronics Forum of New England, pp. 43- 49, 1997.

[3]. Sinha, S. N., and M.Jain, “A self-affine fractal multiband antenna,” IEEE Antenna and Wireless Propagation Letters, vol. 6, pp. 110-112, 2007.

[4]. K.Shambavi, Zachariah C Alex, "Printed Dipole Antenna with Band Rejection Characterstics for UWB Applications,” IEEE Antenna Wireless Propagation Letter, vol.9, pp 1029-1032, Nov 2010.

[5]. Venoy KJ, Abraham JK and Varadan VK. "Fractal dimension and frequency response of fractal shaped antennas," Proc. IEEE Antennas Propagation Soc. int. Symposium, pp. 222-225, 2015.

[6]. Basil K Jeemon, K Shambavi, Zachariah C Alex, "A Multi-fractal Antenna for WLAN and WiMAX application," IEEE Conference on Information and Communication Technologies (ICT),pp 2013.

[7]. Sachin Chauhan, Jitendra Kr. Deegwal, Rachna Gera, “A Design of Triangular Sierpinski Gasket Fractal Antenna," IJECT, vol. 4, Issue no -4, April - June 2013.

[8]. Ananth Sundaram, Madhurima Maddela, and Ramesh Ramadoss, "Koch-Fractal Folded-Slot Antenna Characteristics," IEEE Antenna and Wireless Propagation letters, vol.6, 2007.

[9]. Sivia JS, Singh A and Kamal TS. "Design of Sierpinski Carpet Fractal Antenna using Artificial Neural Networks," International Journal of Computer Applications, pp. 5-10, 2013.

[10]. Singh AP, Sivia JS and Kamal TS, "Estimation of Feed position of rectangular Microstrip Antenna using Artificial Neural Antenna," Institute of Engineer Journal Electronics and Telecommunication pp. 20-25, 2010.

[11]. Constantine A. Balanis “Antenna Theory Analysis and Design,” 2nd Edition ,Wiley India (p.) Ltd., 2007

International Journal of Engineering Research and Applications (IJERA) is UGC approved Journal with Sl. No. 4525, Journal no. 47088. Indexed in Cross Ref, Index Copernicus (ICV 80.82), NASA, Ads, Researcher Id Thomson Reuters, DOAJ.

Lovepreet Singh. "Design And Performance Analysis of Rectangular Microstrip Patch Antenna With Half-Hexagonal Fractal Techniques." International Journal of Engineering Research and Applications (IJERA) 7.7 (2017): 15-19. 